Uşak Üniversitesi Sosyal Bilimler Dergisi

$2014,7 / 2$

\title{
Üniversite Öğrencileri İçin Derse Katılım Ölçeklerinin Geliştirilmesi
}

Ali ERYILMAZ*

\section{Özet}

$\mathrm{Bu}$ çalışmanın amacı, üniversite öğrencilerinin derse katılım düzeylerini belirleyebilecek bir ölçme aracı geliştirmektir. Bu çalışma, 17-25 yaşları arasında yer alan (yaş ortalaması 20.79 ve standart sapması 2.06 olan) lisans öğrenimi gören 209 (105 kadın ve 104 erkek ) üniversite öğrencisi üzerinde gerçekleştirilmiştir. Çalışmada, Alan Genel Algılanan Kontrol ölçeği ve açık uçlu sorular aracılığı ile veriler toplanmıştır. Çalışmada, açımlayıcı faktör analizi, korelasyon analizi ve bazı güvenirlik analizleri yapılmıştır. Çalışmadan elde edilen bulgulara göre, derse genel olarak katılım ölçeği ve belirli bir derse katlım ölçeği olmak üzere üçer boyutlu iki katılım ölçeğine ulaşılmıştır. Ölçeklerin boyutları; duygusal katılım, bilişsel katılım ve davranışsal katılım olarak isimlendirilmiştir. Analiz sonuçlarına göre geliştirilen ölçeklerin güvenirlik ve geçerlik değerleri kabul edilebilir sınırlar içerinde bulunmuştur. Geliştirilen ölçekle ilerleyen süreçte çeşitli araştırmalar yapılabilir ve bu ölçek öznel iyi oluşu artırma programlarında kullanılabilir.

Anahtar Kelimeler: Derse katılım, üniversite öğrencileri, ölçek.

\section{The Development of the Scales of Classroom Engagement for University Students}

\begin{abstract}
In the present study, the development of the scales of class engagement is considered. 209 university students (105 female and 104 male) were included in the present study. The ages of university students range between 17 and 25. In this study, data were obtained through the use of the Domain General Perceived Control Scale and open ended questions, and also data were analyzed through using of explatory factor analysis and reliability analysis, and also content analysis methods. The findings obtained indicate that it is found two important types of scales which are named "general class engagement scale" and "specific class engagement scale" which have three important dimensions: cognitive engagement, behavioural engagements,
\end{abstract}

\footnotetext{
* Doç. Dr. Eskişehir Osmangazi Üniversitesi Eğitim Fakültesi, Eğitim Bilimleri Bölümü, Psikolojik Danışmanlık ve Rehberlik ABD, erali76@hotmail.com
} 
and emotional engagements. Results suggest that the scales are valid and reliable instruments. Results of this study may be used for future researches Key words: Class engagement, university students, scale.

\section{Giriş}

Öğrenciler bir yılda; yaklaşık 180 gün ve günde 6 saatlerini okulda ve sinıfta geçirmektedirler (Eryılmaz, 2013a). Bu süre zarfında bazı öğrenciler aktif bir şekilde derslere katılırken bazıları ise katılmamaktadır. Kimileri için bu geçen süre zarfı çok sıkıcı olmakta kimileri için ise çok keyifli geçmektedir (Eryılmaz ve Dereli, 2011). Öğretmenlerin sınıfta ve okulda bulunma amaçları, öğrencilerin okula ve derse katılımlarını sağlamaktır. Ayrıca, öğrencilerin öğrenmelerini kontrol etmek de bir diğer amaçtır (Ames, 1992; Jimerson, Campos \& Greif, 2003). Etkili öğretim için sadece sinavlarla değil hemen her gün öğrencilerin öğrenme süreçlerinin kontrol edilmesi gerekmektedir. Bu sürecin en önemli öğesini, okula ve derslere katılım oluşturmaktadır.

Katılım konusunun literatürde çok boyutlu olarak ele alındığı görülür. Örneğin katılım konusu, okulu terk etmek, okuldan kaçmak, okuldaki müfredat dişı etkinliklere katılmak, okulda ve sınıfta gerçekleştirilen öğretim faaliyetlerinin içerisinde aktif bir şekilde yer almak gibi boyutlarda incelenmektedir (Barton,2004; Finn, 1989; Kushman, Sieber \& Heariold-Kinney 2000; Natriello, 1984; Newmann, Wehlage \& Lamborn, 1992; McCombs \&Whisler, 1997; Strong, Silver \& Robinson, 1995; Voekl, 1997). Tüm bu boyutların yanında Reschly ve Christenson (2006) katılımın bilişsel, duygusal ve davranışsal olmak üzere üç önemli boyutunun olduğunu belirtmektedir. Davranışsal katılım; ders çalışma, ödevleri yapma, okuldaki müfredat dışı faaliyetlere yönelme ve sınıf için etkinliklerde ve öğrenme süreçlerinde aktif bir şekilde yer alma anlamına gelmektedir. Bilişsel katılım ise; öğrencilerin konuları bilişsel süreçlerine dahil etmeleri, okulda ve sınıfta işlenen konuların gelecekle ve günlük yaşamla ilişkilerinin kurulması, yeni bilgilerin eski bilgilerle ilişkilendirilmesi, öğrencilerin öğrenme amaçlarının olması ve öğrenmeye değer vermeleri anlamına gelmektedir. Duygusal katılım ise öğretmenlerle ve akranlarla olumlu ilişkiler kurmak, derse katılmaya istek duymak, merak ve ilgi duygularıyla sınıf içersinde yürütülen öğrenme faaliyetlerinde yer almak, okula aidiyet duygusu hissetmek anlamina gelmektedir. Reschly ve Christenson (2006), duygusal katılımın bazen psikolojik katılım olarak da ele alındıklarını belirtmektedirler.

\section{Araştırmanın Amacı}


Literatürde gerçekleştirilen çalışmalar, okula ve derslere katılmanın; konuları daha iyi öğrenmeyle ve akademik açıdan daha donanımlı olmayla; akademik güçlüklerin üstesinden gelmeyle ve akademik alanda yapılan etkinliklerden hoşnut olmayla ilişkili olduğunu ortaya koymuştur (Bomia ve ark., 1997; Kenny, Kenny ve Dumont, 1995; Pintrich ve De Groot, 1990). Derse katılma düzeyleri düşen öğrencilerin; derslerden sıkıldıkları, dersin dışındaki konuları düşündükleri, okuldan kaçtıkları, dikkatlerini konu üzerinde yoğunlaştırmakta sorunlar yaşadıkları öğrenim hayatlarını başarıyla tamamlayamadıkları bulunmuştur (Barton, 2004; Christenson, Sinclair, Lehr \& Hurley, 2000). Bu çalışmaların sonuçları, öğrencilerin hem öğrenmelerini yüksek düzeyde tutmak hem de öğrenme sürecinden keyif almalarını sağlamak gerektiğini göstermektedir. Bu amaçlara ulaşmanın önemli bir yolu, öğrencilerin derse katılımlarına yönelik çalışmalarda bulunmaktır. Literatür incelendiğinde üniversite öğrencilerinin derse katılımlarını ölçebilecek bir ölçme aracının olmadığı görülmektedir. Sonuç olarak bu çalışmada üniversite öğrencilerinin derse katılımlarını ölçebilecek ölçeklerin geliştirilmesi amaçlanmıştır.

\section{Yöntem}

$\mathrm{Bu}$ çalışmanın amacı, üniversite öğrencilerinin hem genel olarak derse katılma düzeylerini hem de herhangi bir dersteki katılım düzeylerini ölçebilecek ölçme araçları geliştirmek ve bu araçların psikometrik özelliklerini incelemektir. Bu amaç doğrultusunda bu çalışmada istatistikî analiz teknikleri olarak açımlayıcı faktör analizi iç tutarlılığa dayalı güvenirlik ve geçerlik analizi yöntemleri kullanılmıştır.

\section{Çalışma Grubu}

$\mathrm{Bu}$ çalışma, 17-25 yaşları arasında yer alan (yaş ortalaması 20.79 ve standart sapması 2.06 olan) 2013-2014 eğitim öğretim yılında Eskişehir Osmangazi Üniversitesi Eğitim Fakültesinde öğrenim gören 209 (105 kadın ve 104 erkek ) üniversite öğrencisi üzerinde gerçekleştirilmiştir. Çalışmada yer alan öğrencilerin 96'sı (\%45.9) sinıf öğretmenliği; 70'i (\%33.5) zihin engelliler öğretmenliği $25^{\prime} \mathrm{i}$ (\%12) psikolojik danışmanlık ve rehberlik ve $18^{\prime} \mathrm{i}$ (\%8.7) din kültürü ve ahlak bilgisi öğretmenliği bölümlerinde öğrenim görmektedirler.

\section{Maddelerin Hazırlanması}

Maddelerin hazırlanmasında, daha önce geliştirilen ölçeklerin maddelerinin incelenmesi bir yol olarak kullanılmıştır. Madde hazırlamada, aynı üniversitede eğitim gören 60 kadın ve 60 erkek öğrenci ile derse katılım konusunda nitel görüşmeler yapılması ikinci bir yol olarak izlenmiştir. Nitel 
görüşmelerde "Derse katılan öğrenci nasıl düşünür ve davranır? Derse katılan öğrenci neler hisseder? Soruları sorulmuştur. Soruların yanıtlarına cümle bazında içerik analizi tekniği uygulanmıştır. Analiz sonucu elde edilen ifadeler öznel ifadelere dönüştürülerek ölçeğin dene formu hazırlanmıştır. Ölçeklerin deneme formlarında toplam 29'ar soru yer almıştır.

Derse Katılma Ölçeklerinin Dış Geçerlik Çalışmasında Kullanılan Veri Toplama Aracı

Derse katılma ölçeklerinin diş geçerlik çalışmasında, "Alan Genel Algılanan Kontrol" ölçeği kullanılmıştır. Bu ölçek 6 maddeden oluşmaktadır ve Eryılmaz (2007) tarafından geliştirilmiştir. Ölçek tek boyutlu olup ölçeğin açıklanan varyansı \% 40 'dır. Ölçeğin iç tutarlılığı 0.70 olarak bulunmuştur.

\section{Bulgular}

\section{Yapı Geçerliği}

Üniversite öğrencilerinin genel ve herhangi bir ders için derse katılmalarına yönelik olarak geliştirilen ölçeklerin yapı geçerliliklerini belirlemek için açımlayıcı faktör analizi çalışmaları yapılmıştır.

Açımlayıcı Faktör Analizi Çalışmaları: Açımlayıcı faktör analizi çalışmasında öncelikle 29 maddelik ölçeklerin deneme formları Varimax Dik Döndürmeye yöntemi ile faktör analizine tabi tutulmuştur. Açımlayıcı faktör analizi yaparken, madde yük değerlerinin 0.30 'dan büyük olma ölçütü ve bir maddenin diğer faktör yük değerleri arasında en az 0.10 fark olması ölçütleri alınmıştır. Bu ölçütleri karşılamayan maddeler atılarak Varimax Dik Döndürme yöntemiyle faktör analizine devam edilmiştir. Sonuç olarak:

Genel Olarak Derslere Katılım Ölçeği: Yapılan analizler sonucunda, örneklem yeterliliği için Kaiser-Meyer-Olkin değeri 0.907 ve Bartlett's Test of Sphericity değeri $1577.654(\mathrm{p}<0.01)$ olarak bulunmuştur. Faktör analizi sonucunda, üç boyutlu ve açıklanan varyansı \%64.04 olan "Genel Olarak Derslere Katılım Ölçeği'ne" ulaşılmıştır. Tablo-1'de Genel Olarak Derslere Katılım Ölçeği'nin faktör yapısına yönelik bulgular verilmiştir.

Ölçeğin birinci boyutunun açıklanan varyansı \%44.99 bulunmuştur. Ölçeğin birinci boyutunda "Derslerde gerçekleşen etkinliklere katırlım, derslere hazırlıklı gelirim, derslerde yeri geldiğinde hocaya sorular sorarım" gibi ifadeler yer almıştır. Bu ifadeler ve literatür bilgileri ışığında ölçeğin birinci boyutu "Davranışsal Katılım" olarak isimlendirilmiştir. Ölçeğin ikinci boyutunun açılanan varyansı \%10.76 bulunmuştur. Ölçeğin ikinci boyutunda "Derslere ilgim yüksektir, derslerde merak duygum yüksektir, dersler benim için eğlenceli geçer ve sınıfta ders anlatılırken mutluyumdur" gibi ifadeler yer almıştır. Bu ifadeler ve literatür bilgileri ışı̆̆ında ölçeğin 
ikinci boyutu "Duygusal Katılım" olarak isimlendirilmiştir. Ölçeğin üçüncü boyutunun açıklanan varyansı \%8.29 bulunmuştur. Ölçeğin üçüncü boyutunda "Derslerde, zihnimde anlatılanları canlandırırım, derslerde anlatılan bilgileri alıp beynimde işlemeye çalışırım, derslerde zihnimde konun gündelik yaşamla ilişkisini kurarım" gibi ifadeler yer almıştır. Bu ifadeler ve literatür bilgileri 1şığında ölçeğin üçüncü boyutu "Bilişsel Katılım" olarak isimlendirilmiştir.

Tablo-1 Genel Olarak Derslere Katılım Ölçeği Faktör Yapısı

\begin{tabular}{cccc}
\hline & \multicolumn{3}{c}{ Faktörler } \\
\cline { 2 - 4 } Maddeler & $\begin{array}{c}\text { Davranıssal } \\
\text { Katılım }\end{array}$ & $\begin{array}{c}\text { Duygusal } \\
\text { Katılım }\end{array}$ & $\begin{array}{c}\text { Bilişsel } \\
\text { Katılım }\end{array}$ \\
\hline 12 &, 840 & & \\
14 &, 818 & & \\
18 &, 801 & & \\
16 &, 658 & & \\
17 &, 591 & & \\
2 & &, 808 & \\
6 & &, 798 & \\
1 & &, 683 & \\
9 & &, 647 &, 839 \\
10 & &, 614 &, 684 \\
26 & & &, 648 \\
25 & & & \\
23 & & & \\
28 & & & \\
21 & & & \\
\hline
\end{tabular}

Belirli Bir Derse Katılım Ölçeği: Yapılan analizler sonucunda, örneklem yeterliliği için Kaiser-Meyer-Olkin değeri 0.924 ve Bartlett's Test of Sphericity değeri $2297.088(\mathrm{p}<0.01)$ olarak bulunmuştur. Faktör analizi sonucunda, üç boyutlu ve açılanan varyansı \%73.71 olan "Belirli Bir Derse Katılım Ölçeği'ne" ulaşılmıştır. Tablo-2'de Belirli Bir Derse Katılım Ölçeği'nin faktör yapısına yönelik bulgular verilmiştir.

Ölçeğin birinci boyutunun açıklanan varyansı \%52.95 bulunmuştur. Ölçeğin birinci boyutunda "Sınıfta ders anlatılırken mutluydum, derse ilgim yüksekti, kendimi dersle bütünleşmiş hissettim, derste merak duygum 
yüksekti, ders benim için eğlenceli geçti" gibi ifadeler yer almıştır. Bu ifadeler ve literatür bilgileri ışığında ölçeğin birinci boyutu "Duygusal Katılım" olarak isimlendirilmiştir. Ölçeğin ikinci boyutunun açıklanan varyansı \%12.75 bulunmuştur. Ölçeğin ikinci boyutunda "Derste söz aldım, derste gerçekleşen etkinliklere katıldım, derse hazırlıklı geldim, derste yeri geldiğinde hocaya sorular sordum" gibi ifadeler yer almıştır. Bu ifadeler ve literatür bilgileri ışığında ölçeğin ikinci boyutu "Davranışsal Katılım" olarak isimlendirilmiştir. Ölçeğin üçüncü boyutunun açıklanan varyansı \%8.01 bulunmuştur. Ölçeğin üçüncü boyutunda "Derste, zihnimde anlatılanları canlandırdım, dersde anlatılan bilgileri alıp beynimde işlemeye çalıştım, dersde zihnimde konun gündelik yaşamla ilişkisini kurdum" gibi ifadeler yer almıştır. Bu ifadeler ve literatür bilgileri ışı̆̆ında ölçeğin üçüncü boyutu "Bilişsel Katılım" olarak isimlendirilmiştir.

Tablo-2 Belirli Bir Dere Katılım Ölçeği Faktör Yapısı

\begin{tabular}{cccc}
\hline & \multicolumn{3}{c}{ Faktörler } \\
\cline { 2 - 4 } Maddeler & $\begin{array}{c}\text { Duygusal } \\
\text { Katılım }\end{array}$ & $\begin{array}{c}\text { Davranışsal } \\
\text { Katılım }\end{array}$ & $\begin{array}{c}\text { Bilişsel } \\
\text { Katılım }\end{array}$ \\
\hline 2 &, 861 & & \\
6 &, 794 & & \\
1 &, 791 & & \\
9 &, 787 & & \\
10 &, 773 & & \\
12 & &, 845 & \\
14 & &, 822 & \\
18 & &, 816 & \\
16 & &, 696 &, 804 \\
17 & &, 692 &, 754 \\
26 & & &, 630 \\
25 & & & \\
23 & & & \\
28 & & & \\
21 & & & \\
\hline
\end{tabular}

\section{Uyum Geçerliği}

Belirli Bir Derse Katılım Ölçeği ve Genel Olarak Derslere Katılım Ölçeğinin, uyum geçerliğini belirlemek için Alan Genel Kontrol Ölçeği ile 
ölçeklerin Pearson Korelasyonuna bakılmıştır. Tablo-3'te ve Tablo-4'te ölçekler arasındaki korelasyon değerleri yer almaktadır.

Tablo-3 Genel Olarak Derslere Katılım Ölçeği İle Algılanan Kontrol Ölçeği Arasındaki Pearson Korelasyonu Sonuçları

\begin{tabular}{lc}
\hline & Algılanan Kontrol Ölçeği \\
\hline Algılanan Kontrol & 1 \\
Duygusal Katılım &, $24^{* *}$ \\
Algılanan Kontrol & 1 \\
Duygusal Katılım &, $28^{* *}$ \\
Davranışsal Katılım &, $32^{* *}$ \\
Bilişsel Katılım &, $35^{* *}$ \\
Ölçek Toplam Puanı &, $36^{* *}$ \\
\hline
\end{tabular}

$\mathrm{p}<0.01$ 
Davranışsal Katılım $\quad, 27^{* *}$

Bilişsel Katılım ,32**

Ölçek Toplam Puanı $\quad$,33**

Tablo-4 Belirli Bir Derse Katılım Ölçeği İle Algılanan Kontrol Ölçeği Arasındaki Pearson Korelasyonu Sonuçları

$\mathrm{p}<0.01$

Tablo-3 ve Tablo-4 incelendiğinde ölçeklerin algılanan kontrol ölçeği ile ilişkileri görülmektedir. Bu noktada gerek ölçeklerin toplam puanları gerekse alt ölçek puanları ile algılanan kontrol ölçeği toplam puanı arasında pozitif yönde ve ortaya yakın düzeyde anlamlı ve önemli ilişkilerin olduğu görülmektedir.

\section{Güvenirlik}

Ölçeklerin güvenirlikleri, Cronbach Alpha iç tutarlık tekniği ile analiz edilmiştir. Analiz sonuçları Tablo-5'te yer almaktadır. Tablo-5'te Belirli Bir Derse Katılım Ölçeği ve Genel Olarak Derslere Katılım Ölçeği'nin iç tutarlık değerleri birlikte verilmiştir. Analiz sonuçları incelendiğinde ölçeklerin güvenilir olduğu sonucuna varılır.

Tartışma ve Sonuç

\begin{tabular}{lcc}
\hline & $\begin{array}{c}\text { Genel Olarak Derslere } \\
\text { Katılım Ölçeği } \\
\text { Cronbach Alpha } \\
\text { Değerleri }\end{array}$ & $\begin{array}{c}\text { Belirli Bir Derse } \\
\text { Katılım Ölçeği } \\
\text { Cronbach Alpha } \\
\text { Değerleri }\end{array}$ \\
\hline $\begin{array}{l}\text { Duygusal } \\
\text { Katılım }\end{array}$ &, 93 \\
$\begin{array}{l}\text { Davranışsal } \\
\text { Katılım }\end{array}$ &, 88 \\
$\begin{array}{l}\text { Bilişsel } \\
\text { Katılım }\end{array}$ &, 86 &, 90 \\
Ölçek Toplam &, 84 &, 93 \\
Puanı & & \\
& & \\
\hline
\end{tabular}


Uluslar arası literatürde katılım konusuyla ilgili uzun yıllar çalışmalar gerçekleştirilmektedir (Barton,2004; Finn, 1989; Kushman, Sieber \& Heariold-Kinney 2000; Jimerson, Campos \& Greif, 2003; Newmann, Wehlage \& Lamborn, 1992; McCombs \&Whisler, 1997; Strong, Silver \& Robinson, 1995; Voekl, 1997). Türkiye'de katılım konusuyla ilgili çeşitli çalışmalar gerçekleştirilmiştir. Örneğin Eryılmaz (2010), derste akış yaşamak, derse hazırlıklı gelmek, olumlu beden ve duygu durumu içerinde olmak ve öğretmenle olumlu ilişkiler kurmak şeklinde dört boyutlu derse katılmaya motive olma ölçeğini geliştirmiştir. Aynı konuda Eryılmaz ve Dereli (2011), ilköğretim öğrencileri üzerinde bir ölçek geliştirme çalışmasında bulunmuşlardır. Eryılmaz (2013b), öğrencinin benlik saygısını zedelememek, olumlu kişilik özelliklerine sahip olmak ve öğrenciyi motive etmek şeklinde boyutları olan derse katılmada öğretmenden beklentiler ölçeğini geliştirmiştir. Yapılan çalışmalar derse katılmaya motive olma ile öznel iyi oluş (Eryılmaz ve Aypay, 2011a), okul tükenmişliği (Aypay ve Eryılmaz, 2011), yaşam amaçları belirleme (Eryılmaz ve Aypay, 2011b) arasında olumlu yönde ilişkilerin olduğu bulunmuştur. Tüm bunların yanında, üniversite öğrencilerinin derse katılım durumlarını ölçebilecek bir ölçeğin geliştirilmediği görülmektedir. Bu noktada bu çalışma literatüre katkı sağlamıştır denilebilir.

$\mathrm{Bu}$ çalışmada, geliştirilen ölçeklerin uyum geçerlilikleri alan genel algılanan kontrol ölçeği ile incelenmiştir. Anılan ölçekle bir inceleme yapmanın nedeni algılanan kontrolün akademik faaliyetlerdeki öneminden kaynaklanmaktadır. Çünkü Skinner'e göre (1996), bireylerin derslere katılmalarında onların algılanan kontrol düzeylerinin yüksek olması önemlidir. Ancak bu çalışmada alan genel algılanan kontrol ölçeği kullanılmıştır. Ölçekler arasındaki ilişkileri bu bağlamda değerlendirmek gerekir. Bu çalışmada geliştirilen ölçeklerin özellikle akademik bağlamlar için geliştirilmiş alan özel algılanan kontrol ölçekleri ile de geçerliliklerinin incelenmesi faydalı olabilir.

Bu çalışmanın ilginç noktalarından biri de genel olarak derslere katılım ölçeğinde en yüksek açıklanan varyansa sahip ölçek boyutunun "davranışsal katılım" boyutudur. Öte yandan belirli bir derse katılım ölçeğinde ise en yüksek açıklanan varyans değerine sahip boyut, duygusal katılım boyutudur. Bu sonuçlar ilginç bir gerçeğin altını çizmektedir. Derse katılım sürecinde bireylerin duygu durumları çok önemlidir. İnsanlar sürekli duygusal deneyimler içerisinde oldukları için uzun süreli olarak geçmişe yönelik duygu durumları hakkında canlı anılara sahip olamayabilmektedirler (Carstensen ve Turk-Charles, 1994). Bu nedenle bu çalışmada kısa süreli olarak derse katılım noktasında, duygusal katılım 
boyutu öne çıkarken uzun süreli katılım boyutunda ise davranışsal katılım boyutu öne çıkmıştır.

Sonuç olarak, bu çalışmada gerek genel olarak gerekse kısa süreli olarak öğrencilerin duygusal, davranışsal ve bilişsel açıdan derse katılımlarını ölçebilecek ölçekler geliştirilmiştir. Yapılan analiz sonucuna geliştirilen ölçeklerin güvenilir ve geçerli oldukları sonucuna varılmıştır. Bu çalışmada geliştirilen ölçeklerin farklı örneklemler üzerinde tekrar güvenirlik ve geçerlik çalı̧̧malarının yapılması literatüre katkı sağlayabilir.

\section{Kaynaklar}

Ames, C. (1992). Classrooms: Goals, structures, and student motivation. Journal of Educational Psychology, 84 (3), 261-271.

Aypay, A., \& Eryılmaz, A. (2011). Relationships of high school sdutent' subjective Well Being and school burnout. International Online Journal of Educational Sciences. 3(1):181-199.

Barton, P. E. (2004).One-third of a nation: Rising dropout rates and declining opportunities. Princeton, NJ: Policy Information Center, Educational Testing Service.

Bomia, L., Beluzo, L., Demeester, D., Elander, K., Johnson, M. \& Sheldon, B. (1997). The impact of teaching strategies on intrinsic motivation. Champaign, IL: ERIC Clearinghouse on Elementary and Early Childhood Education. (ED 418 925)

Carstensen, L., \& Turk-Charles, S. (1994). The Salience of Emotion across the Adult Life Span. Psychology \& Aging, 9(2), 259-264.

Christenson, S. L., Sinclair, M. F., Lehr, C. A., \& Hurley, C. M. (2000). Promoting successful school completion. In D. Minke \& G. Bear (Eds.), Preventing school problems - promoting school success: Strategies and programs that work ( $p$. $377-420)$. Bethesda, MD: National Association of School Psychologists.

Eryılmaz, A. (2007). Alan genel algılanan kontrol ölçeğinin geliştirilmesi. I. Psikoloji Öğrencileri Lisansüstü Öğrencileri Kongresi Bildiri Metinleri, İzmir Ekonomi Üniversitesi Yayınları No: 15, s. 62-68.

Eryılmaz, A. (2010). Okulda motivasyon ve amotivasyon ölçeklerinin geliştirilmesi. XVI. Ulusal Psikoloji Kongresi. Mersin Üniversitesi, Mersin.

Eryılmaz, A, \& Aypay, A. (2011a). The relationship between adolescents'motivation to class engagement and their level of subjective well-being. International Journal of Human Sciences, 8:1220-1233. 
Eryılmaz ,A, \& Aypay, A. (2011b). Lise öğrencilerinde derse katılmaya motive olma ile yaşam amaçları belirleme arasındaki ilişkiler. Ahi Evran Üniversitesi Ĕ̆itim Fakültesi Dergisi, (12) 3, 149-158.

Eryllmaz, A. (2013a). Using of positive psychology on psychological counseling and guidance context on character strength and preventive services. The Journal of Happiness $\mathcal{E}$ Well-Being, 1(1), 1-20.

Eryılmaz, A. (2013b). Okulda motivasyon ve amotivasyon: "derse Katılmada öğretmenden beklentiler ölçeği'nin" geliştirilmesi. Mehmet Akif Ersoy Üniversitesi Eğitim Fakültesi Dergisi, 13, 25, 1 - 18.

Eryılmaz, A., \& Dereli, E. (2011). Derse katılmama durumundaki zaman yönelimi ölçeğinin psikometrik özellikleri. İlköğretim Online, 11781190.

Finn, J. D. (1989). Withdrawing from school. Review of Educational Research, 59, 117 - 142.

Jimerson, S. R., Campos, E.,\& Greif, J. L. (2003). Toward an understanding of definitions and measures of school engagement and related terms. California School Psychologist, 8, 7 - 27.

Kenny, G., Kenny, D. \& Dumont, R. (1995). Mission and place: Strengthening learning and community through campus design. Oryx/Greenwood.

Kushman, J.W., Sieber, C., \& Heariold-Kinney, P. (2000). This isn't the place for me: School dropout. In D.Capuzzi \& D.R. Gross (Eds.), Youth at risk: A prevention resource for counselors, teachers, and parents (3rd ed., pp. 471-507). Alexandria, VA: American Counseling Association.

McCombs, B.L., \& Whisler, J.S. (1997). The learner-centered classroom and school: Strategies for increasing student motivation and achievement. San Francisco, CA: Jossey-Bass.

Natriello, G. (1984). Problems in the evaluation of students and student from secondary schools. Journal of Research and Development in Education, $17,14-24$.

Newmann, F. M., Wehlage, G. G., \& Lamborn, S. D. (1992). The significance and sources of student engagement. In F. M. Newmann (Ed.), Student engagement and achievement in American secondary schools (pp. 11 -39). NewYork: Teachers College Press.

Pintrich, P.R. \& De Groot, E. (1990). Motivational and self-regulated learning components of classroom academic performance. Journal of Educational Psychology, 82(1), 33-50.

Reschly, A., \& Christenson, S. L. (2006). Research leading to a predictive model of dropout and completion among students with mild disabilities and the role of student engagement. Remedial and Special Education, 27, 276-292. 
Skinner, E.A. (1996). A guide to consructs of control. Journal of Personality and Social Pscyhology, 71, 549-570.

Strong, R., Silver, H.F., \& Robinson, A. (1995). What do students want? Educational Leadership, 53(1), 8-12.

Voelkl, K. E. (1997). Identification with school. American Journal of Education, 105, 295-319. 